\title{
Luminescence properties of $\mathrm{SrSi}_{2} \mathrm{O}_{2} \mathrm{~N}_{2}$ doped with divalent rare earth ions
}

\author{
Volker Bachmann ${ }^{\mathrm{a}, \mathrm{b}, *}$, Thomas Jüstel ${ }^{\mathrm{a}, \mathrm{c}}$, Andries Meijerink ${ }^{\mathrm{b}}$, Cees Ronda ${ }^{\mathrm{a}, \mathrm{b}}$, \\ Peter J. Schmidt ${ }^{\mathrm{a}}$ \\ ${ }^{\text {a }}$ Philips Research Laboratories, Weisshausstr. 2, D-52066 Aachen, Germany \\ ${ }^{\mathrm{b}}$ Department of Condensed Matter, Debye Institute, Utrecht University, P. O. Box 80 000, 3508 TA Utrecht, The Netherlands \\ ${ }^{\mathrm{c}}$ University of Applied Sciences Münster, Stegerwaldstr. 39, D-48565 Steinfurt, Germany
}

Received 19 August 2005; accepted 18 November 2005

Available online 28 December 2005

\begin{abstract}
The optical properties of $\mathrm{SrSi}_{2} \mathrm{O}_{2} \mathrm{~N}_{2}$ doped with divalent $\mathrm{Eu}^{2+}$ and $\mathrm{Yb}^{2+}$ are investigated. The $\mathrm{Eu}^{2+}$ doped material shows efficient green emission peaking at around $540 \mathrm{~nm}$ that is consistent with $4 \mathrm{f}^{7} \rightarrow 4 \mathrm{f}^{6} 5 \mathrm{~d}$ transitions of $\mathrm{Eu}^{2+}$. Due to the high quantum yield $(90 \%)$ and high quenching temperature $(>500 \mathrm{~K})$ of luminescence, $\mathrm{SrSi}_{2} \mathrm{O}_{2} \mathrm{~N}_{2}: \mathrm{Eu}^{2+}$ is a promising material for application in phosphor conversion LEDs. The $\mathrm{Yb}^{2+}$ luminescence is markedly different from $\mathrm{Eu}^{2+}$ and is characterized by a larger Stokes shift and a lower quenching temperature. The anomalous luminescence properties are ascribed to impurity trapped exciton emission. Based on temperature and time dependent luminescence measurements, a schematic energy level diagram is derived for both $\mathrm{Eu}^{2+}$ and $\mathrm{Yb}^{2+}$ relative to the valence and conduction bands of the oxonitridosilicate host material.
\end{abstract}

(C) 2005 Elsevier B.V. All rights reserved.

Keywords: Luminescence conversion; Divalent lanthanides; Oxonitrides; Phosphor converted LEDs; Ytterbium; Europium

\section{Introduction}

An exciting new development in the field of luminescent materials is the search for new phosphors for the conversion of the near-UV or

\footnotetext{
*Corresponding author. Tel.: + 492416003342 ; fax: +492416003483 .

E-mail address: Volker.Bachmann@philips.com (V. Bachmann).
}

blue emission from (In,Ga)N LED's into visible light. In the past, luminescence research has mainly focused on conventional phosphors for the conversion of $254 \mathrm{~nm}$ UV radiation from a mercury discharge into visible light. Research has contributed to the development of a mature product with stable and efficient $(90 \%$ quantum efficiency) phosphors and, at present, work on phosphors for fluorescent tubes is aimed at incremental improvements in the stability, 
morphology and efficiency of existing phosphors. Luminescence conversion of near-UV or blue light into longer wavelength radiation applied in stateof-the-art white LED lamps poses new challenges in phosphor research, especially, in view of the small energy difference between pump and emission wavelength. In the search for new phosphors for inorganic LEDs, luminescent materials with high charge densities between activator and its surroundings are investigated. Doping such materials with $\mathrm{Ce}^{3+}$ or $\mathrm{Eu}^{2+}$ can lead to strong absorption in the near-UV to blue spectral range combined with efficient emission in the visible. For example, oxides like $\mathrm{Y}_{3} \mathrm{Al}_{5} \mathrm{O}_{12}: \mathrm{Ce}^{3+}$ (YAG:Ce) or sulfides like $\mathrm{CaS}: \mathrm{Eu}^{2+}$ are currently applied in phosphor-converted LEDs (pcLEDs) as luminescence converters [1,2]. Nevertheless, pronounced temperature quenching of luminescence and low chemical stability restricts their use in LED lighting applications where a long device life time under harsh conditions is required.

Oxonitridosilicates, known as siones, represent a class of solid compounds, which can be formally derived from oxosilicates by partial substitution of oxygen by nitrogen. They can combine attractive material properties like high mechanical hardness and strength; also, exceptional thermal and chemical stability is reported [3]. Higher condensed siones are known to be highly covalent and stable towards oxidation and hydrolysis [3]. The $\mathrm{SrSi}_{2} \mathrm{O}_{2} \mathrm{~N}_{2}$ host lattice we are about to report was developed in a synthesis approach that earlier led to efficient nitridosilicate phosphors $\mathrm{M}_{2} \mathrm{Si}_{5} \mathrm{~N}_{8}: \mathrm{Eu}^{2+}$ $(\mathrm{M}=\mathrm{Sr}, \mathrm{Ba})$ [4-6]. The strong interest in this class of novel materials is reflected by a number of publications in the last few years on the system $\mathrm{Ln}-\mathrm{Si}-\mathrm{O}-\mathrm{N}(\mathrm{Ln}=\mathrm{La}, \mathrm{Gd}, \mathrm{Y})$ in general [7] and the title compound in detail [8-12]. This paper describes the synthesis and continuative studies on the optical properties of luminescent materials based on the $\mathrm{SrSi}_{2} \mathrm{O}_{2} \mathrm{~N}_{2}$ host lattice doped with divalent rare earth ions, viz. $\mathrm{Eu}^{2+}$ and $\mathrm{Yb}^{2+}$. The luminescence properties are investigated and the luminescence mechanism is discussed. The luminescence characteristics of the $\mathrm{Eu}^{2+}$-doped $\mathrm{SrSi}_{2} \mathrm{O}_{2} \mathrm{~N}_{2}$ are shown to be very promising for application in pcLEDs. This is substantiated by a recent paper on an all-nitride, phosphor-converted white light emitting diode using the $\mathrm{Eu}^{2+}$-doped title compound [13]

\section{Experimental methods}

All samples were synthesized by a conventional solid-state reaction. Mixtures of $\mathrm{SrCO}_{3}$ (Philips Lighting Components, 99.9\%), $\mathrm{Si}_{3} \mathrm{~N}_{4-x}(\mathrm{NH})_{3 / 2 x}$ $(x \approx 1$, made by thermal decomposition of $\mathrm{Si}(\mathrm{NH})_{2}$ as described in Ref. [14], O conten$\mathrm{t}<2 \mathrm{wt} \%$ ), and the rare earth dopants $\mathrm{Eu}_{2} \mathrm{O}_{3}$ (Alfa Aesar, REacton 99.999\%) or $\mathrm{Yb}_{2} \mathrm{O}_{3}$ (Auer-Remy, 99.99\%) were prepared by ball milling, and fired for $2-4 \mathrm{~h}$ at $1200-1500{ }^{\circ} \mathrm{C}$ in a reducing atmosphere $\left(\mathrm{H}_{2} / \mathrm{N}_{2}\right)$ in a tube furnace. After milling the raw product, powders were washed with water and isopropanol. XRD analysis was done on a Philips diffractometer PW 1729 at $\mathrm{RT}$, using $\mathrm{Cu} \mathrm{K}_{\alpha}$ radiation.

Luminescence spectra were recorded between 4 and $300 \mathrm{~K}$ on a Spex Fluorolog 2 spectrofluorometer equipped with a helium flow cryostat. The setup is described in detail in Ref. [15]. To study thermal quenching between 300 and $600 \mathrm{~K}$, luminescence spectra were measured on a modified spectrofluorimeter system FL900 of Edinburgh Instruments using a Xe-lamp as excitation source. The spectra were measured with a spectral resolution of $0.5-1.0 \mathrm{~nm}$. The complete set-up was described earlier [16]. Luminescence life time measurements were measured using a Lambda Physik dye laser pumped by a Lambda Physik LPX100 excimer laser (operating at $308 \mathrm{~nm}$ ) for pulsed excitation at $450 \mathrm{~nm}$ using a Coumarin 47 dye. Luminescence decay curves were measured using a $0.25 \mathrm{~m}$ Acton Research monochromator and an RCA C31034 photomultiplier tube in combination with a Tektronix Digital Oscilloscope.

\section{Experimental results}

\subsection{Crystal structure}

Phase purity of $\mathrm{SrSi}_{2} \mathrm{O}_{2} \mathrm{~N}_{2}$ samples was checked by means of X-ray powder diffraction. The crystal 
structure is similar to the structure of $\mathrm{CaSi}_{2} \mathrm{O}_{2} \mathrm{~N}_{2}$ [17]. Both compounds represent a new class of layered materials with layers of $\left(\mathrm{Si}_{2} \mathrm{O}_{2} \mathrm{~N}_{2}\right)^{2-}$ that consist exclusively of $\mathrm{SiON}_{3}$-tetrahedrons. The $\mathrm{N}$ atom bridges three $\mathrm{Si}$ atoms, while the $\mathrm{O}$ atom is bound terminally to the $\mathrm{Si}$ atom. There are four types of sites for the $\mathrm{Sr}^{2+}$ ions, each surrounded by six oxygen atoms in a distorted trigonal prismatic manner [18]. The XRD patterns of the $\mathrm{SrSi}_{2} \mathrm{O}_{2} \mathrm{~N}_{2}$ phases described in this paper show similarities to the pattern assigned to a high temperature (HT) phase of $\mathrm{SrSi}_{2} \mathrm{O}_{2} \mathrm{~N}_{2}$ in Ref. [19].

\section{2. $\mathrm{SrSi}_{2} \mathrm{O}_{2} \mathrm{~N}_{2}: \mathrm{Eu}^{2+}$}

The room temperature excitation and emission spectra of the $\mathrm{Eu}^{2+}$-doped $\mathrm{SrSi}_{2} \mathrm{O}_{2} \mathrm{~N}_{2}$ are shown in Fig. 1. The emission spectrum shows a single emission band peaking at $539 \mathrm{~nm}$. The position and width of the emission band differs from that reported for a $\mathrm{SrSi}_{2} \mathrm{O}_{2-\delta} \mathrm{N}_{2+2 / 3 \delta}: \mathrm{Eu}(\delta \sim 1)$ compound with a similar XRD pattern [12], and is comparable with the emission spectrum of a phase that was described as the high-temperature modification of $\mathrm{SrSi}_{2} \mathrm{O}_{2} \mathrm{~N}_{2}: \mathrm{Eu}$ [11]. The emission band is assigned to the $4 \mathrm{f}^{6} 5 \mathrm{~d}^{1} \rightarrow 4 \mathrm{f}^{7}$ (fd) transition on $\mathrm{Eu}^{2+}$. The Stokes' shift (SS) of the fd emission can

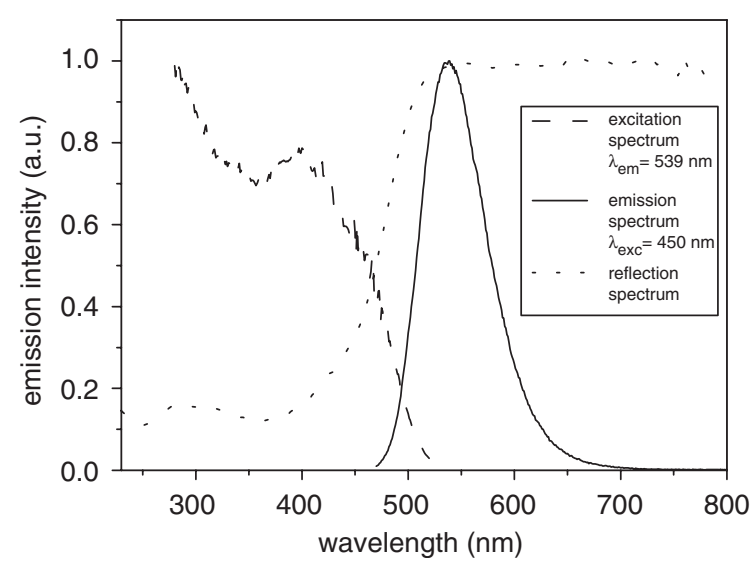

Fig. 1. Luminescence excitation (dashed line) for $539 \mathrm{~nm}$ emission, emission (drawn line) for $450 \mathrm{~nm}$ excitation and diffuse reflection spectrum (doted line) of $\mathrm{SrSi}_{2} \mathrm{O}_{2} \mathrm{~N}_{2}: \mathrm{Eu}^{2+} 2 \%$, recorded at $298 \mathrm{~K}$. be estimated by taking twice the energy difference between the zero phonon line energy and the energy of the emission maximum [20]. The spectral position of the zero phonon line was taken to be the point of intersection of absorption and emission spectrum, $\lambda_{0-0}=494 \mathrm{~nm}(2.51 \mathrm{eV})$. This yields a value of $0.42 \mathrm{eV}$ for $\mathrm{SS}$, which is a typical value for the fd emission from $\mathrm{Eu}^{2+}[20,21]$. For example, in aluminates, silicates and phosphate host lattices, SSs are reported between 0.25 and $1 \mathrm{eV}$ for fd emission from $\mathrm{Eu}^{2+}[20,21]$. The fullwidth at half-maximum (FWHM) of the emission band is $0.3 \mathrm{eV}$, and is slightly smaller than the FWHM as is commonly observed for $\mathrm{Eu}^{2+} \mathrm{fd}$ emission [22]. The position of the emission band is at longer wavelengths than for $\mathrm{Eu}^{2+}$ in oxosilicates [23] showing $\mathrm{Eu}^{2+}$ emission typically in the blue spectral region [24]. One of a few exceptions is $(\mathrm{Ba}, \mathrm{Sr})_{2} \mathrm{SiO}_{4}: \mathrm{Eu}^{2+}$ which emits in the green to yellow spectral range, viz. $520-580 \mathrm{~nm}$ [21]. The shift of the emission to a longer wavelength is ascribed to a higher degree of covalency between the activator ion and its surroundings (nephelauxetic effect) [25]. For $\mathrm{SrSi}_{2} \mathrm{O}_{2} \mathrm{~N}_{2}: \mathrm{RE}^{2+}$ the bonding situation is comparable to orthosilicates like $\mathrm{M}_{2} \mathrm{SiO}_{4}: \mathrm{RE}^{2+}$, where the $\mathrm{RE}$ dopant is coordinated by only O-atoms as well [25]. However, due to the higher degree of condensation of the $\mathrm{SrSi}_{2} \mathrm{O}_{2} \mathrm{~N}_{2}$ lattice, the stability against hydrolysis is much higher compared to alkaline earth orthosilicates.

The decay time of the fd emission of $\mathrm{Eu}^{2+}$ is short, since the transition involved is parity allowed. Typical values are around $1 \mu$ s [24]. In Fig. 2a the luminescence decay curves for the $\mathrm{Eu}^{2+}$ emission are shown for various temperatures between 4 and $723 \mathrm{~K}$. All decay curves show a single exponential decay behavior. Between 4 and $450 \mathrm{~K}$ the decay time $\tau_{1 / e}$ is $1.15 \mu \mathrm{s}$, close to the typical value for the fd emission from $\mathrm{Eu}^{2+}$. It has been shown that the radiative decay time of the $\mathrm{Eu}^{2+} \mathrm{fd}$ emission decreases with increasing energy of the emission maximum, in agreement with the theoretical relation between the radiative transition probability and the energy of electric dipole transition [24]. The radiative decay rate $A_{\mathrm{R}}(=1 /$ $\left.\tau_{1 / e}\right)$ is proportional to the third power of the energy of the emission band ( $\sigma$, energy in 

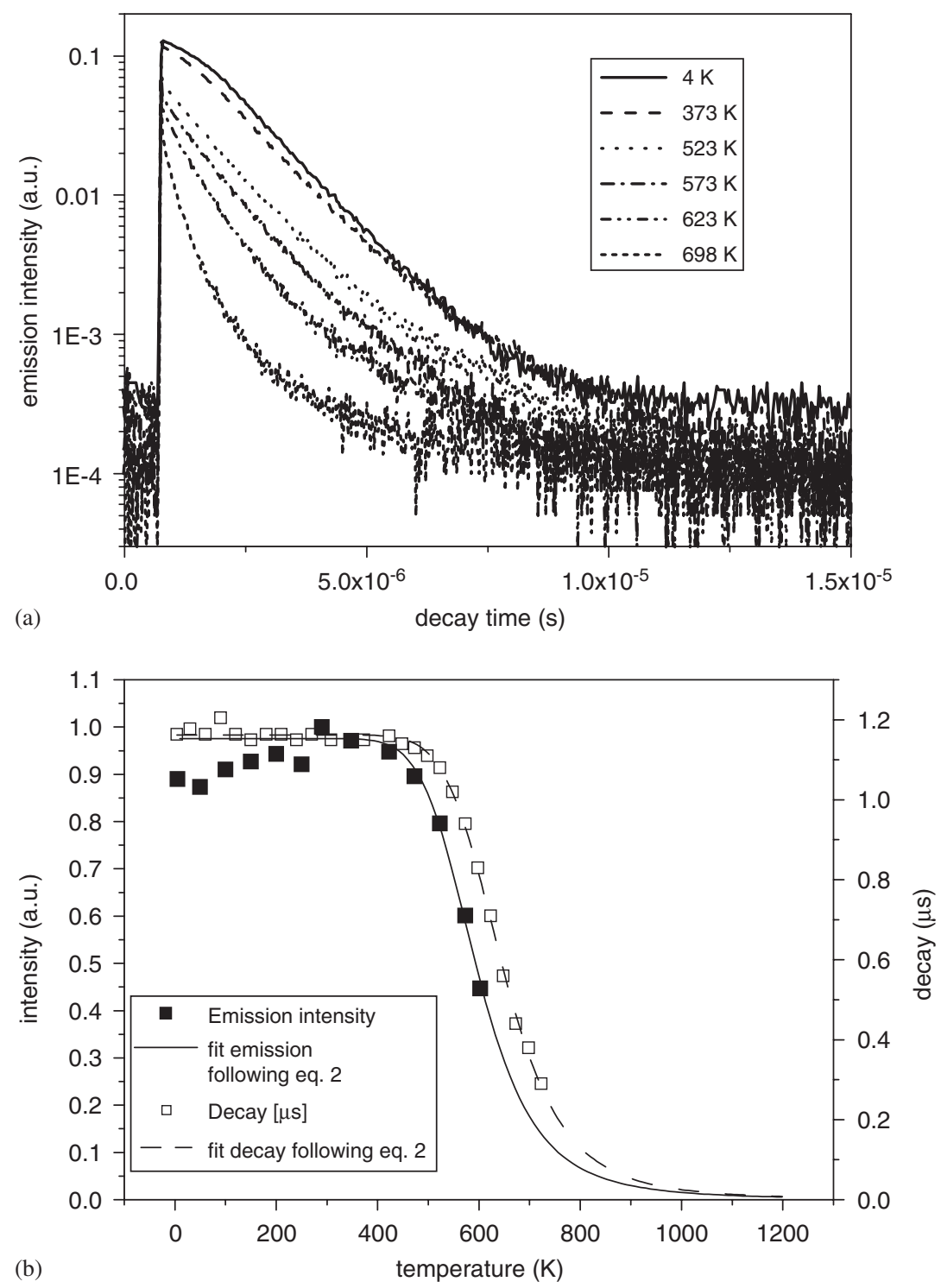

Fig. 2. (a)Temperature dependent decay curves of the $\mathrm{Eu}^{2+}$ emission (for $539 \mathrm{~nm}$ emission under $450 \mathrm{~nm}$ excitation) $\mathrm{SrSi}_{2} \mathrm{O}_{2} \mathrm{~N}_{2}: \mathrm{Eu}^{2+}$ $2 \%$; (b)temperature dependence of the integrated emission intensity (black squares) and luminescence decay times (open squares) derived from the curves in (a). The lines through the data points are fits to Eq. (2).

$\left.\mathrm{cm}^{-1}\right)[24]:$

$A_{\mathrm{R}}(\mathrm{Eu})=\frac{1}{\tau}=5.06 \times 10^{-8}|\langle 5 \mathrm{~d}|r| 4 \mathrm{f}\rangle|^{2} \chi \sigma^{3}$,

where $\langle 5 \mathrm{~d}|r| 4 \mathrm{f}\rangle$ is the radial overlap integral and $\chi$ equals $\left(n\left(n^{2}+2\right)^{2}\right) / 9$, and corrects for the dependence of $A_{\mathrm{R}}$ on the refractive index $n$ [24]. With $\langle 5 \mathrm{~d}|r| 4 \mathrm{f}\rangle=0.81$ [24] and $n=1.75$ (esti- mated from the refractive index reported for similar oxonitridosilicate [26-28], the value for $\chi=$ 5 and the calculated radiative life time is $0.94 \mu \mathrm{s}$. This is very close to the experimentally observed decay time $(1.15 \mu \mathrm{s})$, and the error is within the uncertainty range caused, e.g., by the fact that the refractive index for $\mathrm{SrSi}_{2} \mathrm{O}_{2} \mathrm{~N}_{2}$ is not known exactly, giving an uncertainty of about $10 \%$ in $\chi$. 
The observation that the experimentally observed luminescence life time is very close to the predicted radiative life time in the temperature regime $4-450 \mathrm{~K}$ indicates that in this temperature range the luminescence quantum efficiency of the $\mathrm{Eu}^{2+}$ emission is close to unity.

Above $450 \mathrm{~K}$ the luminescence decay time decreases as is shown in Fig. 2b. The decrease in the luminescence decay time above $450 \mathrm{~K}$ is accompanied by a decrease in the emission intensity indicating that non-radiative relaxation sets in above $450 \mathrm{~K}$. In Fig. $2 \mathrm{~b}$ both the temperature dependence of the luminescence life time and the luminescence intensity are plotted. For the plot of the emission intensity care has been taken to take changes in the absorption due to thermal broadening into account. An analysis based on the thermal broadening of the absorption band and the Kubelka-Munk model for the reflection shows that the changes in reflection over the temperature investigated is less than $5 \%$, and will not significantly influence the measured luminescence intensity. From the temperature dependence of the luminescence decay time and the emission intensity, the luminescence quenching temperature (temperature at which the luminescence intensity has decreased to half its initial values) is estimated to be about $600 \mathrm{~K}$. Current high brightness LEDs can reach temperatures around $450 \mathrm{~K}$. At this temperature the thermal quenching of the fd luminescence of $\mathrm{Eu}^{2+}$ in $\mathrm{SrSi}_{2} \mathrm{O}_{2} \mathrm{~N}_{2}$ is marginal.

The mechanism for quenching of the fd luminescence of $\mathrm{Eu}^{2+}$ may be either quenching by thermally activated cross-over from the $4 \mathrm{f}^{6} 5 \mathrm{~d}$ excited state to the $4 \mathrm{f}^{7}$ ground state, or thermally activated photoionization from the $4 \mathrm{f}^{6} 5 \mathrm{~d}$ state to the conduction band. The former mechanism is historically the most widely used explanation, and for a proper analysis of the temperature dependence of the luminescence intensity the StruckFonger model can be used [29]. More recently, it has been shown that in several host lattices thermally induced ionization of the $5 \mathrm{~d}$ electron is responsible for the quenching of the $\mathrm{Eu}^{2+} \mathrm{fd}$ luminescence [30]. Especially for host lattices, where the SS for the fd emission is small and, yet, the quenching temperature for the lumines- cence is low, it is clear that thermally induced ionization from the fd state to the conduction band is responsible for temperature quenching of the luminescence. Confirmation has been obtained by temperature dependent photoconductivity experiments [31]. In the present composition the SS is small and the luminescence quenching temperature is relatively high, and there is no clear proof for either of the mechanisms being responsible for the temperature quenching. Based on the results for $\mathrm{Yb}^{2+}$ (vide infra) it is likely that the $5 \mathrm{~d}$ state of $\mathrm{Eu}^{2+}$ is close to the conduction band edge, and that thermally activated ionization from the $4 \mathrm{f}^{6} 5 \mathrm{~d}$ state is responsible for temperature quenching of the luminescence. In this case, the temperature dependence of the luminescence intensity and decay time are described by a modified Arrhenius equation. This equation is easily derived by taking the radiative and thermally activated non-radiative decay into account.

$\tau(T)=\frac{\tau_{0}}{1+\tau_{0} C \mathrm{e}^{-E_{\mathrm{A}} / k T}}, \quad I(T)=\frac{I_{0}}{1+D \mathrm{e}^{-E_{\mathrm{A}} / k T}}$,

where $\tau(T)$ and $I(T)$ are luminescence decay time and intensity at temperature $T[K]$, respectively, $\tau_{0}$ and $I_{0}$ the decay time and intensity at $0 \mathrm{~K}, C$ is a rate constant for the thermally activated escape as is $D$ which contains $I_{0}$ as well, $E_{\mathrm{A}}$ is the activation energy for this process which is the energy gap between the $\mathrm{Eu}^{2+} 4 \mathrm{f}^{6} 5 \mathrm{~d}^{1}$ excited level and the bottom of the conduction band, and $k$ is the Boltzmann constant. The intensity at $0 \mathrm{~K}$ was normalized to 1 . In Fig. $2 b$ the best fits to this equation are shown for both the emission and the luminescence decay time. The energy gap $E_{\mathrm{A}}$ for the best fits of emission intensity and decay time is $0.6 \mathrm{eV}$ (marked as 2 in Fig. 4). For the emission intensity, $D$ and $I_{0}$ are $2.76 \times 10^{4}$ and 0.976 , respectively. For the decay time, $C$ and $\tau_{0}$ are $4.24 \times 10^{10}$ and $1.16 \mu \mathrm{s}$, respectively.

The optical band gap of the $\mathrm{SrSi}_{2} \mathrm{O}_{2} \mathrm{~N}_{2}$ host lattice can be obtained from the reflection spectrum of the undoped host lattice. In Fig. 3 the reflection spectrum is shown. The band edge is situated at $220 \mathrm{~nm}$, which shows that the band gap is around $5.6 \mathrm{eV}$. Together with the information of the energy difference between the lowest $4 f^{6} 5 d$ 


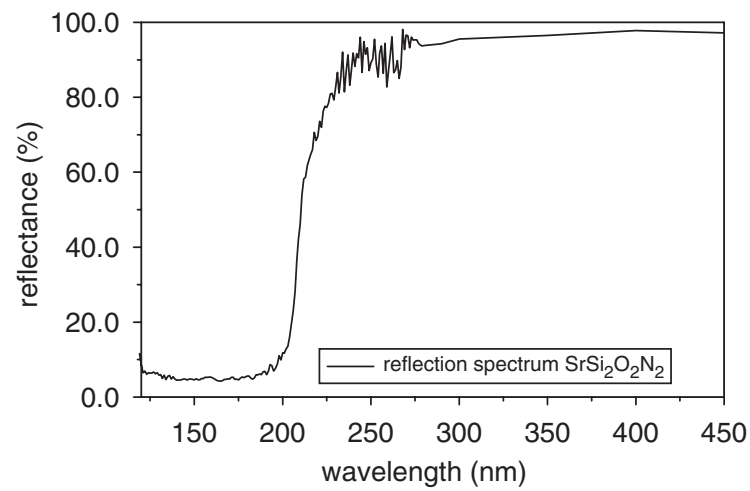

Fig. 3. Diffuse reflection spectrum of undoped $\mathrm{SrSi}_{2} \mathrm{O}_{2} \mathrm{~N}_{2}$ $(T=298 \mathrm{~K})$. See Ref. [6] for experimental details.

state and the $4 \mathrm{f}^{7}$ ground state (for which the energy of the zero-phonon line, $2.5 \mathrm{eV}$, marked as 1 in Fig. 4, is used) a complete energy level diagram for the $\mathrm{Eu}^{2+}$ ion in the $\mathrm{SrSi}_{2} \mathrm{O}_{2} \mathrm{~N}_{2}$ host lattice can be derived. The diagram is shown on the left hand side in Fig. 4. In this diagram, the $4 \mathrm{f}^{7}$ ground state is situated $2.5 \mathrm{eV}$ above the top of the valence band. Note that, although useful as a schematic picture, one should realize that in this type of diagrams energies from results for relaxed and unrelaxed excited configurations are combined in one diagram.

The temperature dependent luminescence properties show that luminescence quenching does not set in below $500 \mathrm{~K}$. A high quenching temperature is important, especially in high brightness LED's where the temperature of the phosphor can increase to about $450 \mathrm{~K}$. The presently used phosphors in white light LEDs suffer from luminescence temperature quenching at these elevated temperatures. The absence of luminescence quenching below $500 \mathrm{~K}$ in combination with the high luminescence quantum yield $(90 \%$ for $\mathrm{SrSi}_{2} \mathrm{O}_{2} \mathrm{~N}_{2}: \mathrm{Eu}^{2+} 2 \%$ ) implies that this material is very promising for application as a luminescence converter in phosphor-converted LEDs [13].

\section{3. $\mathrm{SrSi}_{2} \mathrm{O}_{2} \mathrm{~N}_{2}: \mathrm{Yb}^{2+}$}

The luminescence properties of $\mathrm{Eu}^{2+}$ and $\mathrm{Yb}^{2+}$ are often quite similar for the same host lattice [22,32-35]. In general, the $4 \mathrm{f}^{13} 5 \mathrm{~d}$ excited state of
$\mathrm{Yb}^{2+}$ is at a slightly higher energy $(\sim 0.1 \mathrm{eV})$ than the $4 \mathrm{f}^{6} 5 \mathrm{~d}$ excited state of $\mathrm{Eu}^{2+}$ resulting in a slightly blue-shifted fd emission for $\mathrm{Yb}^{2+}$. In Fig. 5 the excitation, emission and reflection spectra are depicted for $\mathrm{Yb}^{2+}$-doped $\mathrm{SrSi}_{2} \mathrm{O}_{2} \mathrm{~N}_{2}$. The lowest energy fd excitation band is around $450 \mathrm{~nm}$, very similar to the position of the lowest energy fd excitation band for $\mathrm{Eu}^{2+}$. Comparing the excitation and reflection spectra of the $\mathrm{Eu}^{2+}$. and $\mathrm{Yb}^{2+}$-doped sample one must come to the conclusion that the crystal field splitting of $\mathrm{Yb}^{2+}$ must be larger than the one for $\mathrm{Eu}^{2+}$. This can be seen in the much more pronounced fine structure for the two $\mathrm{Yb}^{2+}$ spectra. Reasons for the larger crystal field splitting are the larger effective nuclear

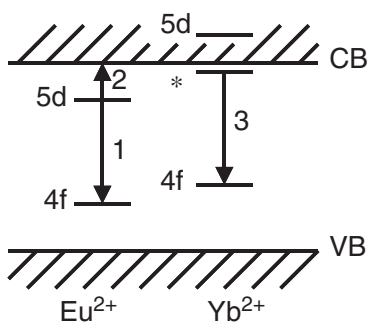

Fig. 4. Energy level diagram for $\mathrm{Eu}^{2+}$ (left-hand side) and $\mathrm{Yb}^{2+}$ (right-hand side) in $\mathrm{SrSi}_{2} \mathrm{O}_{2} \mathrm{~N}_{2}$ derived from luminescence measurements. ${ }^{*}$ emissive state of the trapped exciton emission of $\left.\mathrm{Yb}^{2+}\right)$. See also text.

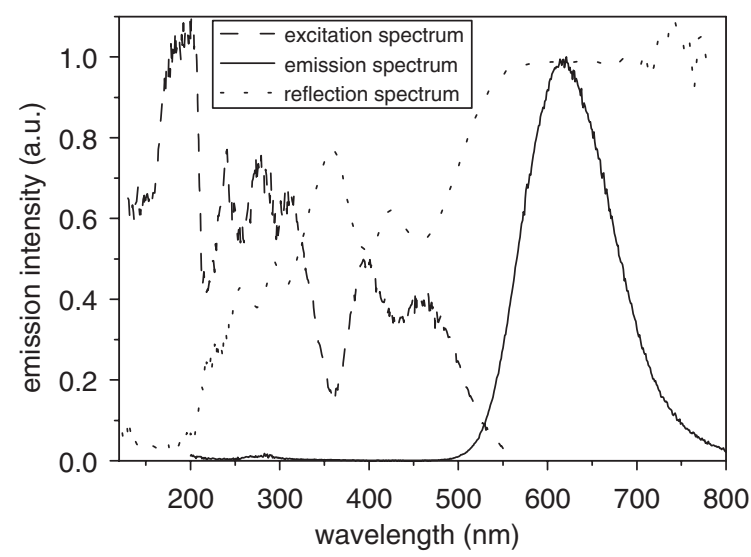

Fig. 5. Excitation spectrum (dashed line) for $615 \mathrm{~nm}$ emission, emission spectrum (drawn line) under $450 \mathrm{~nm}$ excitation and diffuse reflection spectrum (dotted line) of $\mathrm{SrSi}_{2} \mathrm{O}_{2} \mathrm{~N}_{2}: \mathrm{Yb}^{2+}$ $2 \%$. All spectra have been recorded at $298 \mathrm{~K}$. 
charge and the smaller atomic radius of $\mathrm{Yb}^{2+}$ at the same formal charge compared to $\mathrm{Eu}^{2+}$. The $\mathrm{Yb}^{2+}$ emission band, however, is strongly redshifted $\left(\lambda_{\max }=620 \mathrm{~nm}\right.$ for $\mathrm{Yb}$ vs. $540 \mathrm{~nm}$ for $\left.\mathrm{Eu}\right)$ and both the FWHM $(0.32 \mathrm{eV}$ for $\mathrm{Yb}$ vs. 0.30 for $\mathrm{Eu})$ and the Stokes shift $(0.54 \mathrm{eV}$ for $\mathrm{Yb}$ vs. $0.42 \mathrm{eV}$ for $\mathrm{Eu})$ are larger than for the $\mathrm{Eu}^{2+}$ emission band. This type of anomalous red-shifted emission has been reported before for $\mathrm{Yb}^{2+}$. For example, in the fluorite host lattices $\mathrm{CaF}_{2}$ and $\mathrm{SrF}_{2}$ it has been observed that for $\mathrm{CaF}_{2}$ the fd luminescence of $\mathrm{Eu}^{2+}$ and $\mathrm{Yb}^{2+}$ are quite similar, but in $\mathrm{SrF}_{2}$ the emission for $\mathrm{Yb}^{2+}$ is red-shifted (rather than slightly blue-shifted), and the emission is characterized by a larger SS and FWHM and a lower luminescence quenching temperature [36]. The anomalous luminescence properties for $\mathrm{Yb}^{2+}$ are explained by considering the position of the lowest energy fd state. The anomalous emission is observed when the lowest energy fd state is situated in the conduction band. When the fd state is at energies higher than the conduction band edge, excitation into the fd state is followed by photoionization and trapping of the electron close to the lanthanide impurity forming an impurity-trapped exciton state. Luminescence is observed from this impurity-trapped exciton state. Convincing evidence for this model was obtained by performing photoconductivity experiments [37,38]. In host lattices where $\mathrm{Yb}^{2+}$ or $\mathrm{Eu}^{2+}$ show the anomalous emission, excitation into the lowest energy fd band gave a clear photoconductivity confirming that the lowest energy fd state is situated in the conduction band. At present, there are a number of oxide and fluoride host lattices in which impurity-trapped exciton emission is observed for $\mathrm{Yb}^{2+}$ and $\mathrm{Eu}^{2+}$ [39]. Moine and coworkers describe in Refs. $[36,40]$ the temperature dependence of $\mathrm{Yb}^{2+}$ emission in $\mathrm{SrF}_{2}$. The present results on $\mathrm{Eu}^{2+}$ - and $\mathrm{Yb}^{2+}$-doped $\mathrm{SrSi}_{2} \mathrm{O}_{2} \mathrm{~N}_{2}$ show that in this oxonitridosilicate the lowest $\mathrm{fd}$ state is below the conduction band for $\mathrm{Eu}^{2+}$ and above the conduction band edge for $\mathrm{Yb}^{2+}$, similar to the situation found for $\mathrm{SrF}_{2}$.

Luminescence decay times have been measured for the $\mathrm{Yb}^{2+}$ emission between 4 and $640 \mathrm{~K}$. In Fig. 6 a the luminescence decay curves are shown for several temperatures. All decay curves are single-exponential. In Fig. $6 \mathrm{~b}$ the luminescence decay times derived from fitting the curves of Fig. 6a to a single exponential function are plotted as a function of temperature. The luminescence decay time at $4 \mathrm{~K}$ is $65 \mu \mathrm{s}$. This is shorter than the low temperature decay time of the fd emission from $\mathrm{Yb}^{2+}$ (typically $10 \mathrm{~ms}$ ), and is in line with the low temperature decay times for impurity $(\mathrm{Yb})$ trapped exciton emission (typically $50-500 \mu \mathrm{s}$ ). The relatively short luminescence decay time supports the assignment of the $\mathrm{Yb}$ emission to impurity-trapped exciton emission. Above $50 \mathrm{~K}$ the luminescence decay time decreases, as is shown in Fig. 6b. There are two possible reasons for this effect. First, thermal quenching may set in leading to an increase in the non-radiative relaxation rate and, therefore, to a decrease of the overall decay time. Second, the thermal population of higher energy levels with faster decay times can explain this decrease. To distinguish between the two scenarios we studied the emission intensity in the same temperature range as the decay time. If nonradiative relaxation is responsible, the intensity is expected to decrease in the same manner as the decrease in decay time. Contrary to this, we found an increase of the emission intensity starting above $50 \mathrm{~K}$. This increase continues when heating the sample further, until a decrease in the emission intensity is observed above $280 \mathrm{~K}$. Based on this observation, it is evident that thermal population of a higher energy level with a faster decay time is responsible for the decrease of the luminescence life time between 50 and $280 \mathrm{~K}$. The increase in emission intensity concurrent with the decrease in life time has been observed before, and is explained by a constant non-radiative decay channel at low temperatures. An increase in the radiative decay rate is in that case accompanied by an increase in luminescence intensity, since the radiative decay channel is favored over the nonradiative channel. Above $280 \mathrm{~K}$, thermal quenching sets in and decreases the emission intensity and causes a further decrease of the decay time. To calculate the activation energy of the thermal quenching we used the emission intensities measured between 280 and $640 \mathrm{~K}$. The best-fit following Eq. (2) gives an activation energy $E_{\mathrm{A}}$ of $0.3 \mathrm{eV}$. From this fit the values for $I_{0}$ and $D$ are $4 \times 10^{6}$ 

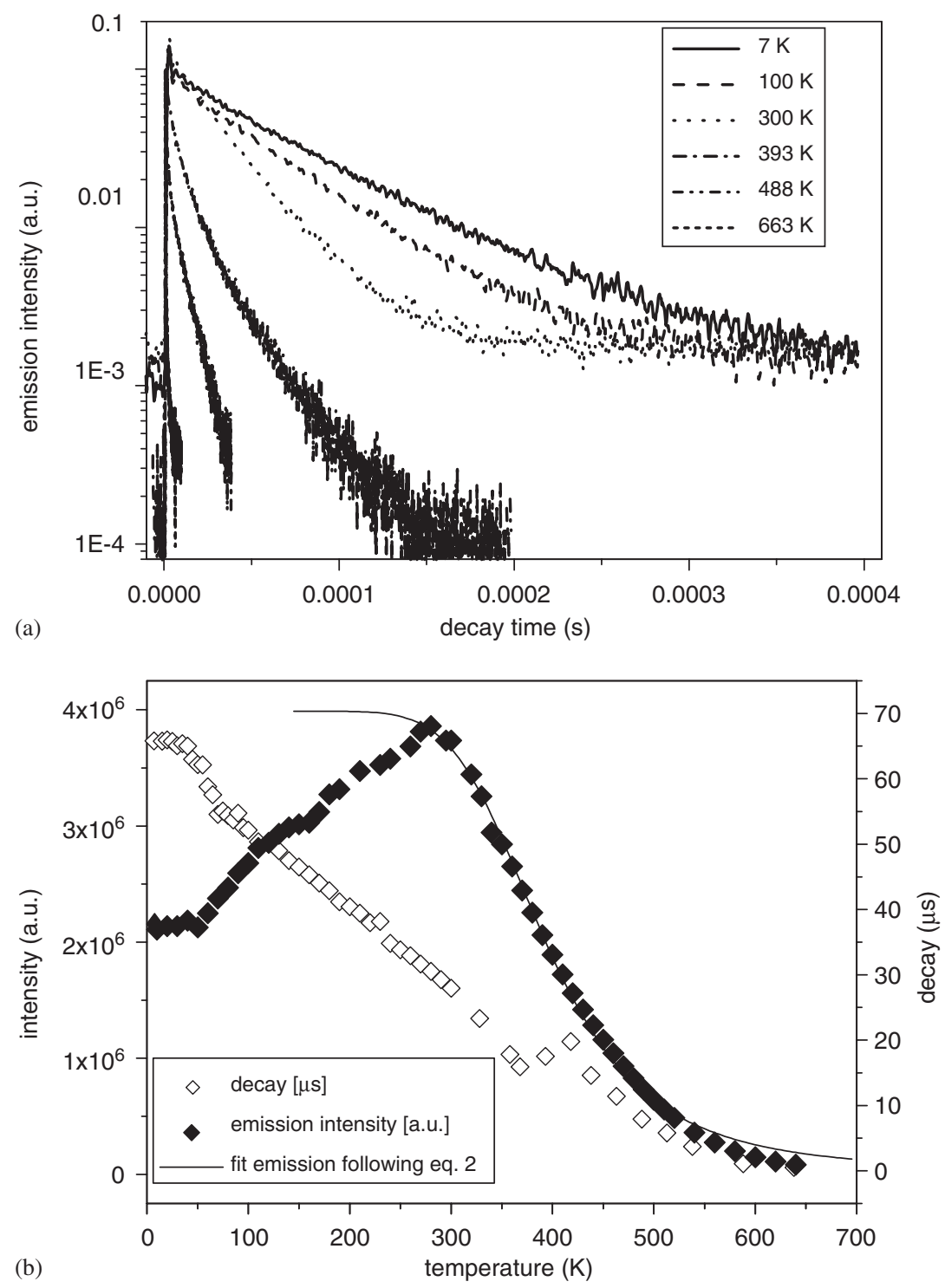

Fig. 6. Temperature dependent decay curves of the $\mathrm{Yb}^{2+}$ emission (for $615 \mathrm{~nm}$ emission under $450 \mathrm{~nm}$ excitation) $\mathrm{SrSi}_{2} \mathrm{O}_{2} \mathrm{~N}_{2}: \mathrm{Yb}^{2+}$ $2 \%$; (b)temperature dependence of the integrated emission intensity (black diamonds) and luminescence decay times (open diamonds) derived from the curves in (a). The lines through the data points are fits to Eq. (2).

and 2441, respectively. Together with the information of the energy difference between the emitting impurity-trapped exciton state (marked as * in Fig. 4) and the $4 \mathrm{f}^{14}$ ground state (for which the energy of the zero-phonon line, $2.3 \mathrm{eV}$, marked in Fig. 4 as 3 , is used) a complete energy level diagram for $\mathrm{Yb}^{2+}$ in the $\mathrm{SrSi}_{2} \mathrm{O}_{2} \mathrm{~N}_{2}$ host lattice can be derived. As shown in Fig. 4, on the right- hand side of the diagram the $4 \mathrm{f}^{14}$ ground state is located $3.0 \mathrm{eV}$ above the valence band.

\section{Conclusions}

The temperature dependence and life times are reported for the $\mathrm{f}-\mathrm{d}$ luminescence of $\mathrm{Eu}^{2+}$ and 
$\mathrm{Yb}^{2+}$ in $\mathrm{SrSi}_{2} \mathrm{O}_{2} \mathrm{~N}_{2}$. For $\mathrm{Eu}^{2+}$ a very efficient $4 \mathrm{f}^{6} 5 \mathrm{~d} \rightarrow 4 \mathrm{f}^{7}$ emission at relatively long wavelength in the green spectral range (around $540 \mathrm{~nm}$ ) is observed. The quenching temperature of the emission is high (no quenching below $500 \mathrm{~K}$ ), and makes $\mathrm{SrSi}_{2} \mathrm{O}_{2} \mathrm{~N}_{2}: \mathrm{Eu}^{2+}$ a promising phosphor for high-power, phosphor-converted LEDs [13]. For $\mathrm{Yb}^{2+}$ an anomalous emission is observed around $615 \mathrm{~nm}$, which is characterized by a large Stokes' shift and a low quenching temperature. The emission is ascribed to an $\mathrm{Yb}^{2+}$-trapped exciton luminescence. Based on the luminescence measurements, an energy diagram is derived in which the positions of local states of $\mathrm{Eu}^{2+}$ and $\mathrm{Yb}^{2+}$ are included, as well as bottom and top of conduction and valence band of the oxonitridosilicate host. For $\mathrm{Eu}^{2+}$, the lowest energy fd state is below the edge of the conduction band, whereas for $\mathrm{Yb}^{2+}$ the lowest fd state is positioned within the conduction band.

\section{References}

[1] P. Schlotter, J. Baur, Ch. Hielscher, M. Kunzer, H. Obloh, R. Schmidt, J. Schneider, Mater. Sci. Eng. B 59 (1999) 390.

[2] Y. Hu, W. Zhuang, H. Ye, S. Zhang, Y. Fang, X. Huang, J. Lumin. 111 (2005) 139.

[3] W. Schnick, Int. J. Inorg. Mater. 3 (2001) 1267.

[4] H. Huppertz, W. Schnick, Acta Crystallogr. C 53 (1997) 1751.

[5] T. Schlieper, W. Milius, W. Schnick, Z. Anorg. Allg. Chem. 621 (1995) 1380.

[6] H.A. Höppe, H. Lutz, P. Morys, W. Schnick, A. Seilmeier, J. Phys. Chem. Sol. 61 (2000) 2001.

[7] J.W.H. van Krevel, On new rare-earth doped $\mathrm{M}-\mathrm{Si}-$ Al-O-N materials, Ph.D. Thesis, Universiteitsdrukkerij TU Eindhoven, Eindhoven, 2000.

[8] V. Bachmann, T. Jüstel, C.R. Ronda, P.J. Schmidt, European Patent EP04106286.0.

[9] P. Schmidt, T. Jüstel, W. Mayr, H.-D. Bausen, W. Schnick, H. Höppe, World Patent WO 2004/036962 A1.

[10] H. Tamaki, S. Kakashima, World Patent WO 2004/039915 A1.

[11] T. Fiedler, F. Jermann, World Patent WO 2005/030905 A1.

[12] Y.Q. Li, A.C.A. Delsing, G. de With, H.T. Hintzen, Chem. Mater. 17 (2005) 3242.
[13] R. Mueller-Mach, G. Mueller, M.R. Krames, H.A. Höppe, F. Stadler, W. Schnick, T. Juestel, P. Schmidt, Phys. Stat. Sol. (A) 202 (2005) 1721.

[14] H. Lange, G. Wötting, G. Winter, Angew. Chem. 103 (1991) 1606.

[15] J.F. Suyver, J.J. Kelly, A. Meijerink, J. Lumin. 104 (3) (2003) 187.

[16] T. Jüstel, J.-C. Krupa, D.U. Wiechert, J. Lumin. 93 (2001) 179.

[17] H.A. Höppe, F. Stadler, O. Oeckler, W. Schnick, Angew. Chem. 116 (41) (2004) 5656.

[18] W. Schnick, private communication.

[19] W.H. Zhu, P.L. Wang, W.Y. Sun, D.S. Yan, J. Mater. Sci. Lett. 13 (1994) 560.

[20] A. Meijerink, G. Blasse, J. Lumin. 43 (1989) 283.

[21] S.H.M. Poort, H.M. Reijnhoudt, H.O.T. van der Kuip, G. Blasse, J. Alloys Comp. 241 (1996) 75.

[22] P. Dorenbos, J. Lumin. 104 (4) (2003) 239.

[23] W.M. Yen, M.J. Weber, Inorganic Phosphors, CRC Press, Boca Raton, FL, USA, 2004.

[24] S.H.M. Poort, A. Meijerink, G. Blasse, J. Phys. Chem. Sol. 58 (9) (1997) 1451.

[25] P. Schmidt, T. Jüstel, C. Clausen, W. Mayr, Meeting Abstracts Volume 2002-1 of the 201st Metting of the Electrochemical Society, Abstract No. 1195.

[26] D.C. Pereyra, M.I. Alayo, Mater. Char. 50 (2003) 167.

[27] K. Worhoff, L.T.M. Hilderink, A. Driessen, P.V. Lambeck, Proceedings ECS, 2001-7, 191.

[28] M. Serenyi, M. Racz, T. Lohner, Vacuum 61 (2001) 245.

[29] C.W. Struck, W.H. Fonger, J. Lumin. 10 (1975) 1.

[30] E.v.d. Kolk, P. Dorenbos, C.W.E. van Eijk, S.A. Basun, G.F. Imbusch, W.M. Yen, Phys. Rev. B 71 (2005) 165120/ 1.

[31] U. Happek, S.A. Basun, J. Choi, J.K. Krebs, M. Raukas, J. Alloys Comp. 303-304 (2000) 198.

[32] S. Lizzo, A. Meijerink, G. Blasse, J. Lumin. 59 (1994) 185.

[33] S. Lizzo, A. Meijerink, G.J. Dirksen, G. Blasse, J. Lumin. 63 (1995) 223.

[34] S. Lizzo, A.H. Velders, A. Meijerink, G.J. Dirksen, G. Blasse, J. Lumin. 65 (1995) 303.

[35] J.W.M. Verwey, G.J. Dirksen, G. Blasse, J. Phys. Chem. Sol. 53 (3) (1992) 367.

[36] B. Moine, B. Courtois, C. Pedrini, J. Lumin. 48 \& 49 (1991) 501

[37] B. Moine, C. Bruna, C. Pedrini, J. Lumin. 45 (1990) 248.

[38] M. Raukas, S.A. Basun, W. van Schaik, U. Happek, W.M. Yen, Mater. Sci. Forum 239-241 (1999) 249.

[39] P. Dorenbos, J. Phys.: Condens. Matter 15 (2003) 2645.

[40] B. Moine, C. Pedrini, D.S. McClure, H. Bill, J. Lumin. 40\&41 (1988) 299. 